Neurosurg Focus 6 (4):Article 8, 1999

\title{
Endoscopic removal of cysticercal cysts within the fourth ventricle: technique and results
}

\section{Marvin Bergsneider, M.D.}

Harbor-UCLA Medical Center, University of California at Los Angeles, Division of Neurosurgery, Los Angeles, California

There is no consensus as to the optimum management of patients who harbor cysticercal cysts within the fourth ventricle. Compared with the alternative treatment options of anthelmintic medication and/or cerebrospinal fluid shunting, the surgical removal of the cyst has the advantage of eliminating the inflammatory nidus and potentially obviating the need for a complication-prone shunt. Here, an endoscopic surgical approach is described and proposed as a superior alternative to the suboccipital craniotomy for removal of a fourth ventricle cyst.

A retrospective analysis was conducted to compare five consecutive endoscopic cases with eight previous consecutive cases in which a suboccipital craniotomy was performed to remove fourth ventricle cysticercal cysts. Comparisons are made with regards to success in removing the cyst, length of operation, surgical blood loss, postoperative discomfort, and complications. A detailed description of the endoscopic technique is given.

Endoscopic removal of all cysts within the fourth ventricle was successful in each case. The mean length of operative times was shorter and the blood loss was reduced with the endoscopic procedure compared with the suboccipital craniotomy $(2.5 \pm 0.8$ hours and $5.3 \pm 2.2$ hours [p $=0.02], 19 \pm 4 \mathrm{ml}$ and $269 \pm 203$ $\mathrm{ml}[\mathrm{p}=0.02]$, respectively). The endoscopic procedure was safe and associated with less postoperative discomfort in most patients.

In properly selected patients, the endoscopic removal of cysticercal cysts located within the fourth ventricle is superior to the suboccipital craniotomy and should be considered as the primary treatment for this condition.

Key Words * cysticercosis * endoscopy * hydrocephalus * arachnoiditis

Cysticercosis is the most common parasitic infection of the central nervous system, with an estimated $50,000,000$ people infected worldwide.[37] Intraventricular involvement occurs in approximately 15 to $20 \%$ of neurocysticercal cases[35] and is associated with significant rates of morbidity and mortality.[12] Most intraventricular cysts are found within the fourth ventricle,[29,43] a location that carries a higher 
risk for brain herniation and development of basilar meningitis.[32] In one study of 24 patients with cysts located in the fourth ventricle, 11 presented with acutely progressive disease courses that prompted emergency admission and urgent ventriculostomy.[3] Although most agree that there is a need to treat these patients, there are several management options and no clear consensus in the literature as to which is optimum. The choice of whether or not to use primarily an anthelmintic medication, a cerebrospinal fluid (CSF) diversionary procedure, and/or the surgical removal of the cyst remains controversial.

In this report, a minimally invasive endoscopic approach for removal of fourth ventricle cysticercal cysts is described. The objectives of this report are to understand the indications for this endoscopic procedure, describe its technical aspects, and compare its surgical efficacy and morbidity with that of the surgical alternative, the standard suboccipital craniotomy.

\section{CLINICAL MATERIAL AND METHODS}

Between November 1995 and October 1998, five consecutive patients underwent endoscopic removal of cysts located within the fourth ventricle at Harbor-UCLA Medical Center. In an unselected retrospective analysis, the surgical and outcome data in these endoscopic cases were compared with the eight prior consecutive cases in which suboccipital craniotomy procedures were performed at the same institution for the same diagnosis. Prior to November 1995, the surgical preference for the management of fourth ventricle cysticercal cysts was a standard suboccipital craniotomy. Suboccipital craniotomy procedures performed prior to 1988 were not analyzed because they predated the availability of magnetic resonance (MR) imaging at this medical center. Unlike the endoscopic procedures, all of which were performed by the author and assisted by a neurosurgical resident, several different attending neurosurgeons performed the suboccipital craniotomy procedures. The comparison between the endoscopic and open craniotomy procedures was limited to 1) success in removal of all cysts within the fourth ventricle, 2) incidence of procedure-related increased neurological deficits, 3) length of the procedure, 4) estimated blood loss, and 5 ) the patient's postoperative surgery-related discomfort, which was judged by the type of analgesic medications used. In the endoscopic group, the mean patient age was 29 years (range 14-40 years), and the average follow-up period was 5 months (range 1-16 months). The mean patient age in the suboccipital craniotomy group was 36 years (range 26-42 years), and the average follow-up period was 36 months (minimum 6 months).

The preoperative management was similar between the two groups. Patients who presented with symptoms of acute hydrocephalus underwent placement of a frontal ventriculostomy. Once the neurological condition was stabilized, definitive neurodiagnostic tests were performed.

Contrast-enhanced MR imaging of the brain was the preferred study; however, in some cases an intraventricular contrast-enhanced computerized tomography (CT) study was performed to confirm the existence of a cyst located in the fourth ventricle. The patients were then scheduled for operation on a semi-urgent basis. Perioperative prophylactic antibiotic agents (cefazolin) and intravenous dexamethasone were given to all patients.

\section{Endoscopic Technique}

The patient is placed in the prone position, the head secured in 3-point rigid skull fixation, and the neck flexed to the same degree that is used in a standard suboccipital craniectomy. The ventriculostomy, if present preoperatively, is kept open to drainage during induction of anesthesia, but afterward it is closed to permit monitoring of intracranial pressure only. A flexible, steerable neuroendoscope must be used. This procedure cannot be performed using a rigid or semi-rigid endoscope. At the time of this writing, 
the Codman 4-mm flexible, steerable neuroendoscope (Johnson \& Johnson Professional, Inc., Raynham, MA) was preferred because it allows for the greatest degrees of maneuverability and flexibility. The endoscope is set up and secured to the accompanying endoscope holder (Johnson \& Johnson Professional, Inc.) attached to a Bookwalter mount. The primary endoscopist stands at the patient's left side and the assistant at the right. The television monitor is situated on the patient's right side, next to the anesthesiologist. A gravity-fed irrigation solution similar in $\mathrm{pH}$ and osmolarity to CSF, such as Plasmalyte (Baxter, Deerfield, IL), is preferable to $0.9 \mathrm{~N}$ saline because the low $\mathrm{pH}$ of the latter may interfere with the respiratory drive while the patient recovers from anesthesia. The irrigation tubing is connected to the endoscope by using an irrigation adapter (Codman Neuroglide; Johnson \& Johnson Professional, Inc.).

A vertical, linear $2.5-\mathrm{cm}$ incision is marked on the skin directly overlying the midline aspect of the posterior arch of $\mathrm{C}-1$. If a ventriculostomy is not already in place, the scalp is shaved in the right occipital area so that an emergency ventriculostomy can be placed if needed. The muscle and connective tissue dissection is limited to an exposure of the posterior arch of C-1 and less than $10 \mathrm{~mm}$ of the opisthion (Fig. 1). A Cloward cervical retractor (Codman, Johnson \& Johnson Professional, Inc.) works well in providing exposure for this small skin and muscle opening. If the craniocaudal exposure of the dura between the opisthion and C-1 is less than $10 \mathrm{~mm}$, a Kerrison rongeur (Codman, Johnson \& Johnson Professional, Inc.) is used to remove 2 to $5 \mathrm{~mm}$ of bone from the posterior portion of the foramen magnum. The vertical, midline incision is made in the dura to within $1 \mathrm{~mm}$ of the bony exposure, and the dural edges are tented back with sutures. The arachnoid is opened under direct visualization. If free cysts are present in the cisterna magna, they will often spontaneously express themselves at this point.

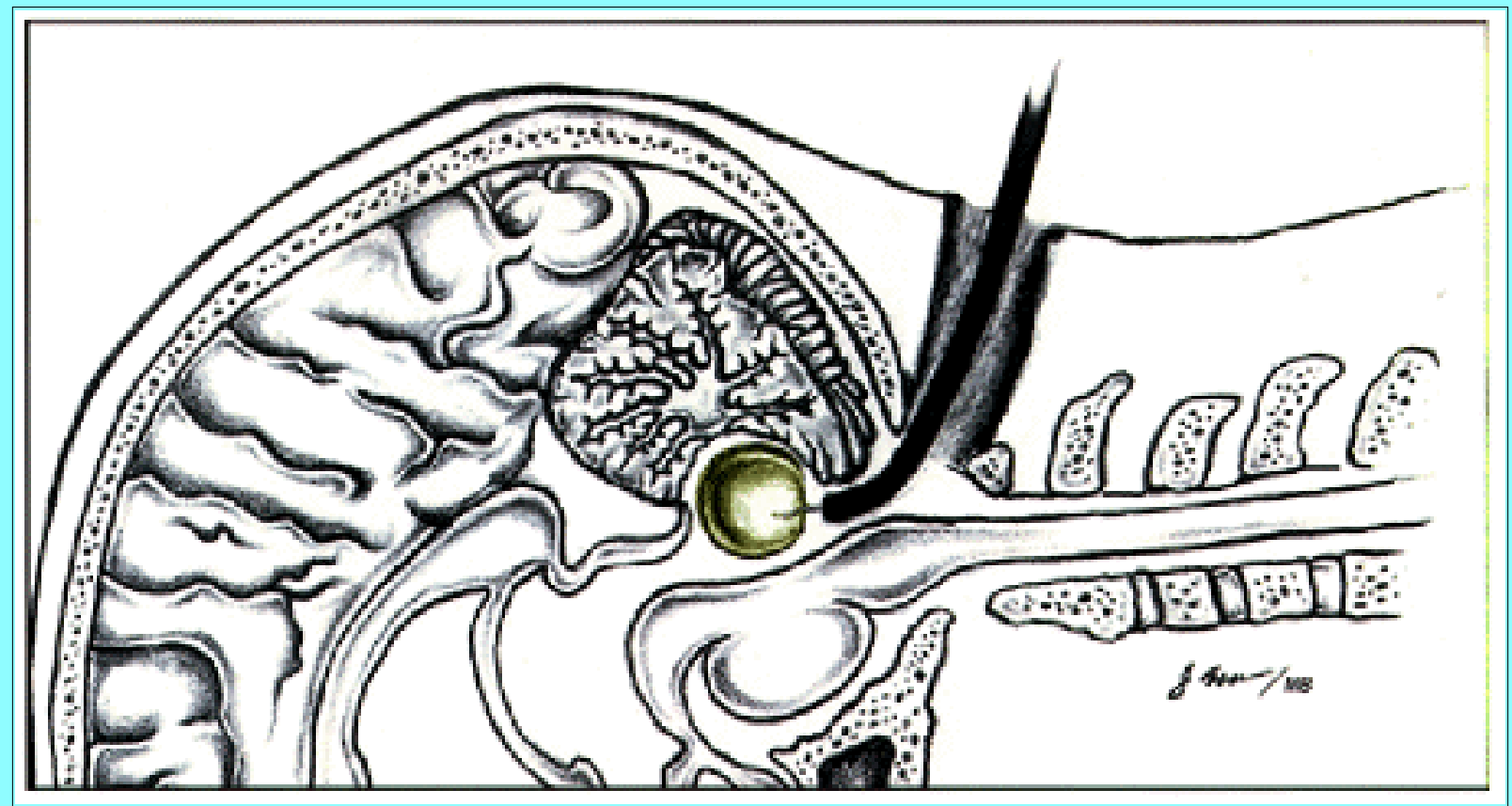

Fig. 1. Artist's illustration depicting the surgical corridor and endoscopic route for removal of a cysticercal cyst located in the fourth ventricle. The midline durotomy is made between the opisthion and the posterior arch of $\mathrm{C}-1$. A flexible endoscope traverses the Magendie's foramen so that a transendoscopic grasping instrument can be used to retrieve the cyst.

Under direct visualization, the tip of the endoscope is positioned at the dural opening. By using continuous irrigation, the endoscope tip is flexed upward as the subarachnoid space is entered (Fig. 1). 
The endoscopic landmarks that must be identified include the brainstem and cervical spinal cord ventrally, and the tonsils of the cerebellum laterally.

\section{Click here to view Video.}

Video. Endoscopic removal of cyst located in the fourth ventricle. The flexible endoscope is navigated between the tonsils of the cerebellum. Both posterior inferior cerebellar arteries are seen leading to the Magendie's foramen. The floor of the fourth ventricle and the choroid plexus are clearly visible. The fourth ventricle is entered with the greenish cysticercal cyst in the midline. The transendoscopic grasper is used to capture the cyst, and the endoscope is withdrawn, with the cyst visible just distal to the tip of the endoscope. The cyst was removed without causing rupture.

The tonsillar branches of each posterior inferior cerebellar artery are landmarks to the midline and the tonsillar vallecula. The endoscope is gently advanced toward the foramen of Magendie using small back-and-forth motions and continuous irrigation to dissect the fine arachnoid bands that are normally present. Often the cyst may be visible protruding out of the Magendie's foramen. The endoscope is advanced slowly using the same dissection technique until the floor of the fourth ventricle is seen. The degree of arachnoidal scarring may vary from minor to near-complete occlusion of the fourth ventricular outlet. If a thickened arachnoid membrane is encountered, it can be fenestrated by using the straight end of a 0.032-inch-diameter vascular guidewire that is passed down the working channel of the endosope. A No. 3 French embolectomy balloon catheter can then be used to expand the small perforation made by the guidewire and thereby gain access to the fourth ventricle.

Once in the fourth ventricle, the cysticercal cyst is easily recognized. The endoscope is then used to inspect the relation of the entire cyst with the ependymal wall and the choroid plexus. The continuous irrigation and the mechanical presence of the endoscope help separate the cyst wall from the ependymal wall and choroid plexus. Once it is confirmed that the cyst is not inseparably adhered to an ependymal surface, the transendoscopic grasping instrument is advanced down the working channel of the endoscope. After grasping the cyst wall, the grasping instrument is pulled back until the cyst is approximately $5 \mathrm{~mm}$ from the distal tip of the endoscope. It is important to maintain visualization of the surrounding fourth ventricle surfaces. No attempt is made to withdraw the cyst via the working channel of the endoscope because this will result in tearing of the cyst wall. The anesthesiologist is asked to perform a gentle and sustained Valsalva manuver (to approximately $30 \mathrm{~mm} \mathrm{Hg}$ airway pressure) while the endoscope is carefully backed out and withdrawn from the dural opening. The cyst is maintained just beyond the distal end of the endoscope and placed in the specimen cup. If the cyst wall tears, some spillage of the contents into the fourth ventricle or subarachnoid space may occur. In such cases, the grasper is reapplied and the withdrawal technique repeated until the entire cyst is removed. The endoscope is navigated back into the fourth ventricle, and additional cysts, if present, are removed using the aforementioned technique. Once all cysts are removed, the fourth ventricle is inspected a final time, and irrigation is continued until any cloudiness of the ventricular fluid has cleared.

The dural opening is closed using interrupted 4-0 nylon sutures in a watertight fashion. The wound is closed in layers in a routine manner. The course of prophylactic antibiotic drugs (cefazolin) and a low-dose dexamethasone ( $4 \mathrm{mg}$ every 6 hours) is maintained for 24 hours.

\section{Suboccipital Craniotomy Technique}


Because there were several different attending surgeons who performed surgery in the craniotomy group, there was likely some variation in surgical technique. Based on a review of the operative reports, however, all surgeons generally used a standard approach, similar to that described by Madrazo and Flisser.[28] In brief, this procedure typically entailed an incision extending from just above the inion to just below the spinous process of $\mathrm{C}-2$. The bony removal included a midline 4 x 6 -cm suboccipital craniectomy combined with resection of the posterior arch of $\mathrm{C}-1$. The dura mater was opened in a Y-shaped fashion, and the cerebellar tonsils were separated for exposure of the floor of the fourth ventricle. In all but one of the cases, an operating room microscope was used to inspect and work within the fourth ventricle.

\section{RESULTS}

The clinical presenting signs and symptoms, intraoperative findings, and outcomes for the endoscopy group are summarized in Table 1. The successful removal of the cysts located in the fourth ventricle was achieved in every case. The only procedure-related complication was postoperative pneumocephalus, which resulted in the patient experiencing delirium that improved over several days without the need for surgical intervention. In one case, the removal of a large cyst (Fig. 2) was associated with a rupture of the cyst wall. In this case, as well as the others, there was no evidence of a postoperative ventriculitis or meningitis. 
TABLE 1

SUMMARY OF CL NICAL FIND NGS AND OUTCOME RESULTS IN PATIENTS UNDERGONG ENDOSCOPK REMOYL OF CVSTICERCAL CVSTS LOCATED WITHN THE FOURTH YENTRICLE*

\begin{tabular}{|c|c|c|c|c|c|}
\hline $\begin{array}{l}\text { Case } \\
\text { No. }\end{array}$ & $\begin{array}{l}\text { Presenting } \\
\text { Symptorns }\end{array}$ & $\begin{array}{l}\text { Neur dimaging } \\
\text { Findngs }\end{array}$ & Irtra op Findings & $\begin{array}{c}\text { Postop } \\
\text { Complications }\end{array}$ & $\begin{array}{c}\text { Outcome } \\
\text { and Follow Up }\end{array}$ \\
\hline 1 & $\begin{array}{l}\text { 2-mo history of } \\
\text { episodic head- } \\
\text { ache, turred } \\
\text { vision }\end{array}$ & $\begin{array}{l}\text { wentricular con- } \\
\text { trast CT dem- } \\
\text { onstrated cyst } \\
\& \mathrm{HC}\end{array}$ & $\begin{array}{l}\text { mild ependymitis, } 10-\mathrm{mm} \\
\text { cyst removed wo rup- } \\
\text { ture }\end{array}$ & $\begin{array}{l}\text { postopintra- } \\
\text { wentricular air } \\
\text { resulted in an } \\
\text { agitated, con- } \\
\text { fused state for } \\
3 \text { days }\end{array}$ & $\begin{array}{l}\text { excellent recowery; } \\
\text { HC resolved }\end{array}$ \\
\hline 2 & $\begin{array}{l}\text { acute obstructie } \\
\text { HC; se'vere up- } \\
\text { mard gaze palsy' } \\
\text { \& tilat 6th crani- } \\
\text { al ner've palsies; } \\
\text { le thargic }\end{array}$ & $\begin{array}{l}\text { wentricular con- } \\
\text { trast CT showed } \\
\text { 4th wentricular } \\
\text { cyst }\end{array}$ & $\begin{array}{l}\text { mild ependymitis, } 12- \\
\text { mm cyst rem oved } \\
\text { whout nupture }\end{array}$ & none & $\begin{array}{l}\text { WP shunt } 6 \text { days af- } \\
\text { ter endoscopic pro- } \\
\text { cedure, wilater re- } \\
\text { vision; } 1 \text { yr later } \\
\text { had continued sei- } \\
\text { zure disorder }\end{array}$ \\
\hline 3 & $\begin{array}{l}\text { 1-mo history of in- } \\
\text { creasing head- } \\
\text { ache, nausea, } \\
\& \text { womiting }\end{array}$ & $\begin{array}{l}\text { CT \& MR demon- } \\
\text { strated communi- } \\
\text { cating } \mathrm{HC} \text { w/ } \\
\text { questionatle le- } \\
\text { sion in } 4 \text { th wentri- } \\
\text { cle on MR }\end{array}$ & $\begin{array}{l}\text { on dural o pening, five } \\
\text { cysts e xpressed them- } \\
\text { selves; ependyma had } \\
\text { high degree of chronic } \\
\text { in tlamm atory changes; } \\
3 \text { cysts removed wi } \\
\text { endosco pe from } 4 \text { th } \\
\text { wentride wh nupture }\end{array}$ & none & $\begin{array}{l}\text { required VP shunt } \\
2 \text { wks later; treat- } \\
\text { ed w/al bendazole; } \\
\text { at } 2 \text { mos FU, had } \\
\text { mild turred vision }\end{array}$ \\
\hline 4 & $\begin{array}{l}\text { under went place- } \\
\text { ment of vP shunt } \\
6 \text { mos pre vious } y_{1} \\
10 \text {-day history of } \\
\text { headache, intrac- } \\
\text { table nausea, } 8 \\
\text { womiting }\end{array}$ & $\begin{array}{l}\text { MR revealed } \\
\text { large } 4 \text { th wen- } \\
\text { tricle w/sight } \\
\text { contrast en- } \\
\text { hancement }\end{array}$ & $\begin{array}{l}\text { extensi ue arachnoidal } \\
\text { scarring at } 4 \text { th ventric- } \\
\text { ular outle trequired } \\
\text { endosco pic fenestra- } \\
\text { ton; } 2 \text { free cysts re- } \\
\text { moved from } 4 \text { th wen- } \\
\text { tricle wh rupture }\end{array}$ & none & $\begin{array}{l}\text { discharged home } \\
36 \text { hrs postop; } \\
\text { asymptomatic at } \\
3 \text { wks FU }\end{array}$ \\
\hline 5 & $\begin{array}{l}1 \text { wk history of } \\
\text { headaches, } \\
\text { nausea, } \& \\
\text { womiting }\end{array}$ & $\begin{array}{l}\text { CT re vealed } \mathrm{HC} \\
\text { many punctate } \\
\text { calcifications; MR } \\
\text { revealed large } \\
\text { cyst win 4th } \\
\text { wentide }\end{array}$ & $\begin{array}{l}\text { mild ependymitis; large } \\
\text { cyst wid } 4 \text { th wentricle } \\
\text { expressed itself on } \\
\text { dural opening after } \\
\text { endosco pic dissection } \\
\text { of cyst from malls of } \\
4 \text { th wentride; cyst rup- } \\
\text { tured during retrieval }\end{array}$ & none & $\begin{array}{l}\text { discharged home } \\
48 \text { hrs postop; } \\
\text { asymptomatic at } \\
4 \text { mos FU }\end{array}$ \\
\hline
\end{tabular}

${ }^{x} \mathrm{FU}=$ follow up; $\mathrm{HC}=$ hydrocephalus. 


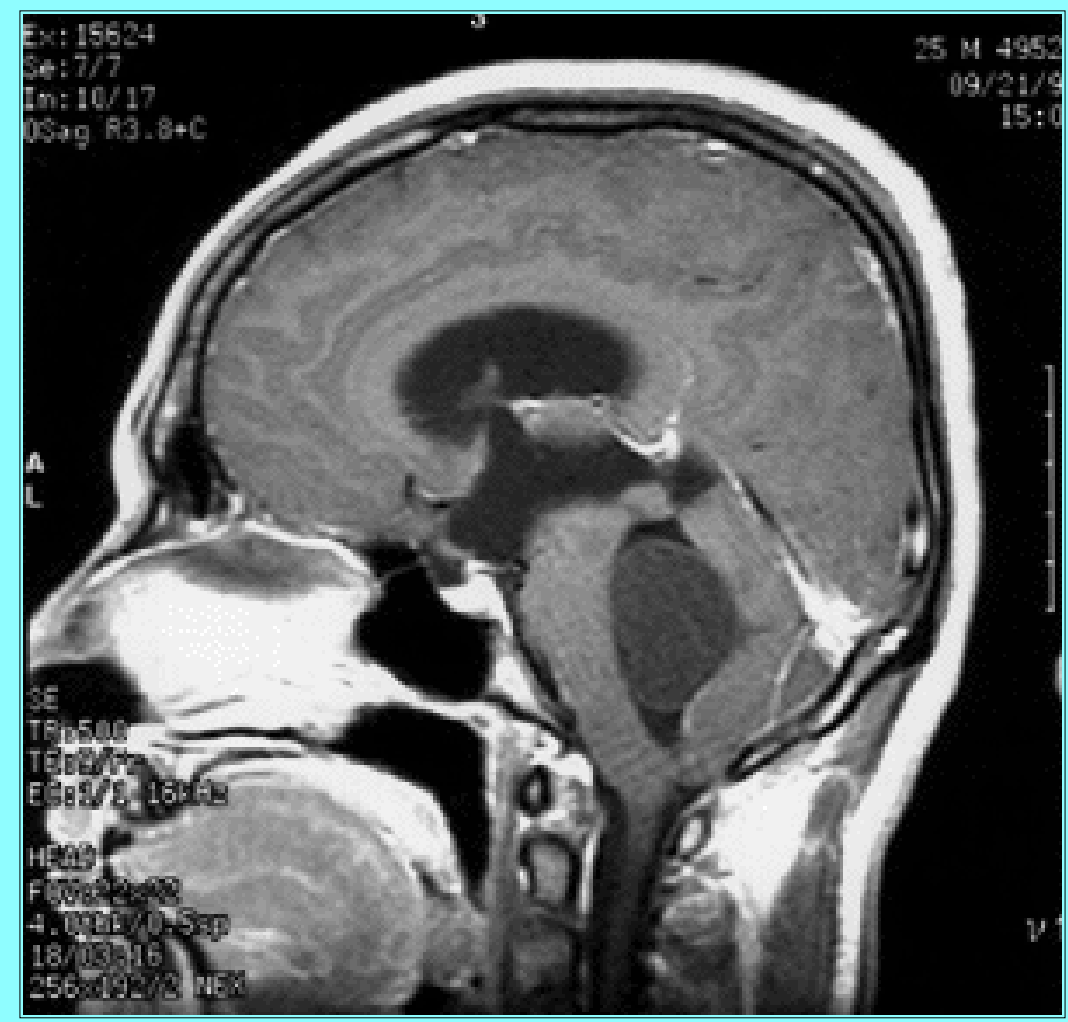

Fig. 2. Sagittal gadolinium-enhanced $\mathrm{T}_{1}$-weighted $\mathrm{MR}$ image demonstrating a 3 -cm-diameter nonenhancing cysticercal cyst within the fourth ventricle. Endoscopic removal of this cyst was associated with rupture of the cyst wall and spillage of the cyst contents. The entire cyst was removed and the patient did not experience any signs or symptoms of ventriculitis postoperatively (Case 5 in Tables 1 and 2). The hydrocephalus was relieved, and this patient did not require a CSF shunt.

Of the five endoscopically treated patients, two patients required subsequent placement of ventriculoperitoneal (VP) shunt for continued hydrocephalus, whereas two others were spared this subsequent procedure. The one patient in whom a VP shunt had been placed previously and who presented with an isolated fourth ventriculitis was successfully treated by removal of the offending cysts (Fig. 3). Although arachnoidal thickening and chronic ependymitis were apparent endoscopically, no significant degree of ependymal enhancement was detected on preoperative contrast-enhanced CT or MR imaging studies. 


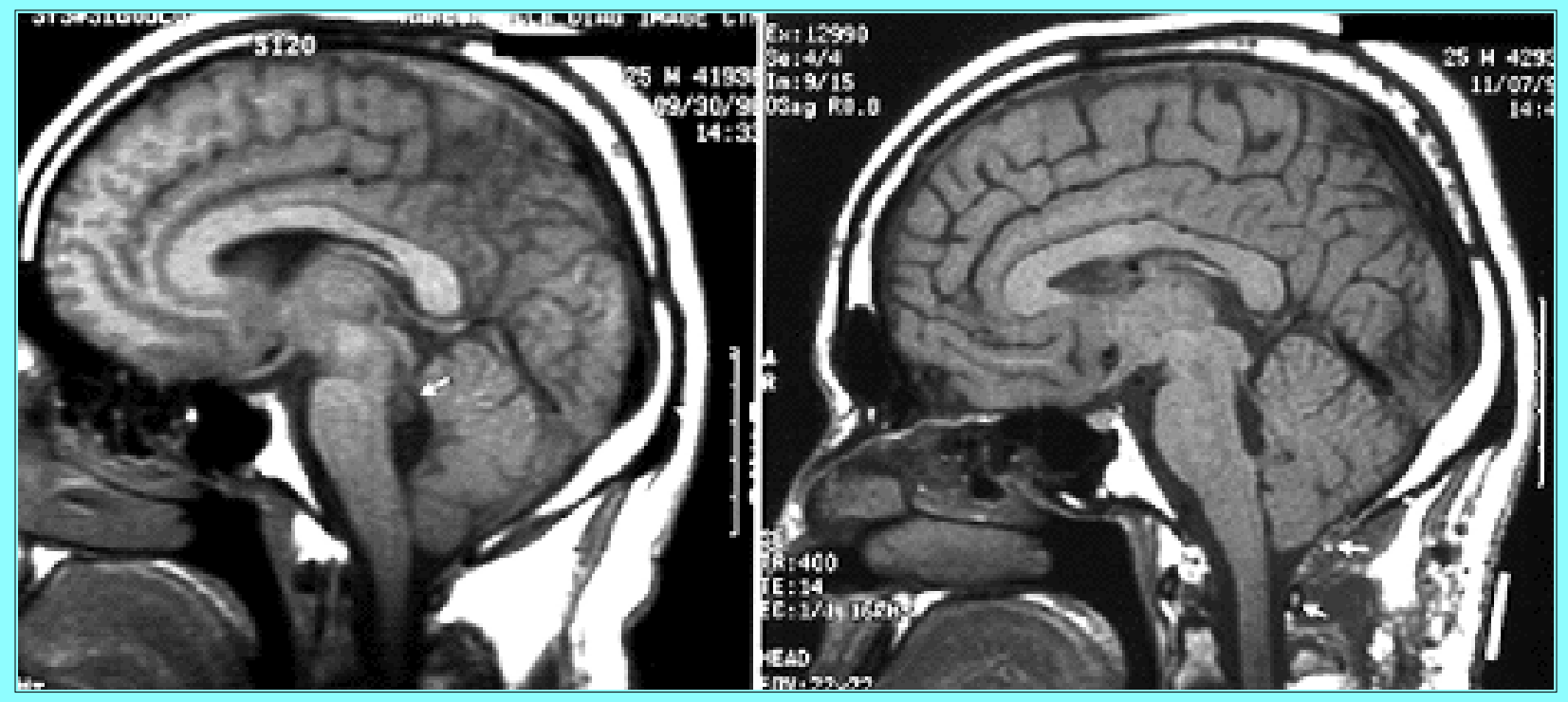

Fig. 3. Sagittal $T_{1}$-weighted MR images. Left: Preoperative study demonstrating an 8-mm cysticercal cyst located in the superior fourth ventricle (white arrow). This lesion showed minimal enhancement with gadolinium (not shown). Right: Study obtained 5 weeks postendoscopic removal of the cyst. Note the limits of the surgical exposure (white arrows and solid white bar). This patient (Case 4 in Tables 1 and 2) presented with intractable nausea and vomiting several months following primary CSF shunt placement. He was asymptomatic postoperatively following removal of the cyst.

A comparison of surgical results, length of operative time, estimated blood loss, postoperative analgesic requirements, and need for a VP shunt in both groups is summarized in Table 2. Removal of cycts located in the fourth ventricle was accomplished in all but one of the cases. This was a craniotomy procedure in which the calcified scolex along the roof of the fourth ventricle was not identified during the procedure. No discrete injuries to the brainstem, cervical spinal cord, or cerebellum were apparent in either group. The mean operative time for the endoscopic procedure, $2.5 \pm 0.8$ hours, was significantly shorter than that for the suboccipital craniotomy, $5.3 \pm 2.2$ hours $(\mathrm{p}=0.02$, independent $\mathrm{t}$-test $)$. In addition, the average estimated blood loss was less as well (endoscopy $19 \pm 4 \mathrm{ml}$, suboccipital craniotomy $269 \pm 203 \mathrm{ml} ; \mathrm{p}=0.02$ ). The morbidity related to postoperative discomfort varied in both procedures, but it is notable that three of the five patients in the endoscopic group required only acetaminophen or nothing at all for pain relief. 
Argument for and Against Primary Anthelmintic Treatment. It has been suggested that albendazole is the treatment of choice for patients in whom hydrocephalus is not present and in whom uncomplicated neurocysticercosis is located in the fourth ventricle.[4,12,37] This is largely based on anecdotal reports of patients with cysts located in the fourth ventricle successfully treated with praziquantel or albendazole.[2,16,17,21,37] Cysts have been documented to disappear as early as the 3rd month after treatment.[12]

Others have argued that neither praziquantel nor albendazole is indicated in the treatment of intraventricular cysticercosis.[19] There are fewer proponents for praziquantel because the results of several studies have shown that it is not effective for intraventricular cysts. $[1,22,38,42]$ Medical treatment does not preclude a surgical intervention because medically treated patients are still at risk of developing acute hydrocephalus.[17] An additional potential drawback of initiating anthelmintic treatment is that it may incite an acute chemical meningitis despite the concomitant administration of glucocorticoids agents.[4] Finally, there is no scientifically convincing evidence to support the contention that either albendazole or praziquantel changes the natural course of the disease. In the only randomized, controlled study performed in patients with the parenchymal form of neurocysticercosis, there was no difference in radiological or clinical outcome between patients treated with anthelmintics and prednisolone compared with prednisolone alone.[7] Because the intraparenchymal form of neurocysticercosis should exhibit the greatest vulnerability to anthelmintic medications, this makes the argument for anthelmintic administration for intraventricular cysts far less convincing.

Argument for and Against a Primary CSF Shunting Procedure. Several groups have suggested that a majority of patients in whom cysticercal cysts are present in the fourth ventricle and in whom hydrocephalus is present can be managed with a shunting procedure alone.[4,8,12,26,32] The potential drawbacks to such an approach, however, are well known and not insignificant. In one study, 46 (82\%) of 56 patients undergoing CSF shunt placement required reoperation due to malfunction of the shunt.[8] Because primary shunting procedures leave the cyst in the fourth ventricle, patients remain at risk for complications, including recurrent hydrocephalus and/or meningitis associated with the death of the parasite. [8,39] In addition, the need for a direct surgical removal of the cyst is not avoided when shunt placement procedures alone are performed. In one report of seven patients undergoing primary VP shunt placement, three patients later required exploration for cyst expansion and development of focal compression signs at 8,11 , and 48 months after the initial procedures.[3] One case of upward herniation has been reported in a patient in whom a cyst was located in the fourth ventricle and who underwent primary ventriculoatrial shunt placement.[14]

Argument for and Against Primary Surgical Removal of the Cyst. Because of the high complication rate associated with shunting procedures and the fact that the location or migration of cysts may produce not only chronic but also acute and possibly lethal clinical progression, many authors recommend surgical extirpation in most cases of ventricular cysts. $[3,8,11,12,17,18,20,26,27,29,30,31,39]$ Due to inherent risks when a cyst is left intact, some authors have proposed that even if a primary shunt procedure is performed, subsequent direct surgical excision of the parasite should be undertaken.[27] The suboccipital craniotomy for direct exposure of the fourth ventricle has been the method used in nearly every reported surgical series of neurocysticercosis.[4,9,10,13,25,28,29,41]

Like primary medical and shunting approaches, the direct surgical approach has drawbacks and limitations as well. The finding of severe ependymitis frequently results in incomplete cyst removal and a high likelihood of requiring a subsequent shunt placement procedure.[3] Whereas certain authors have 
considered intraoperative cyst rupture a dangerous event, $[29,30]$ others do not share this view.[3,26,27,36] The surgeon must consider the possibility of an uneventful surgical exploration secondary to migration of the cyst from the fourth ventricle during the time period between the imaging study and the operation.[24,44] Lastly, all surgical procedures carry an inherent risk of morbidity and mortality, the degree of which depends on the technique used and the experience of the surgeon.

There has been only one report of a case in which an endoscopic exploration of the fourth ventricle was performed in a patient with neurocysticercosis. No cyst was found, and technical aspects of the procedure were not described.[37] The endoscopic approach to cysticercal cysts within the lateral and third ventricles has been reported by several authors.[3,5,6,33,34] These operations typically involve an endoscopic transcortical approach to the lateral and third ventricles, an option far less appealing in the posterior fossa. Instead, access to the fourth ventricle is gained via a transvallecular approach that does not involve injury to normal structures.

\section{Efficacy and Safety of the Endoscopic Approach to the Fourth Ventricle}

Based on results from this series, the endoscopic approach was a safe, effective surgical treatment for the removal of cysticercal cysts located within the fourth ventricular in these selected patients. Compared with the suboccipital craniotomy, endoscopy required less operating-room time, was associated with less blood loss, and produced less postsurgical discomfort. There were no permanent deficits associated with the endoscopic approach.

Potential drawbacks and limitations of the endoscopic approach exist. Because the endoscope slides on top of the surface of the brainstem, this procedure requires an endoscope that is both flexible and steerable, as well as an experienced neuroendoscopist to perform the surgery. Rupture of the cyst during withdrawal can occur, although there were no postoperative sequelae in this series. The complication of postoperative pneumocephalus did occur following one endoscopic procedure; however, this complication is not unique to endoscopy because some degree of pneumocephaly occurs in approximately $60 \%$ of cases in which posterior fossa craniotomies are performed in the prone position.[23]

How successful and safe the endoscopic approach would be for patients in whom MR imaging demonstrates a significant degree of ependymal enhancement is not known. It is likely that these patients are poor candidates for an endoscopic procedure because the reported experience with the suboccipital approach has been disappointing. As noted previously, in such patients a markedly worsened prognosis, irrespective of the management chosen, is generally expected.

The results of this study demonstrate that an endoscopic approach for the removal of cysticercal cysts located within the fourth ventricle is comparable to the suboccipital craniotomy in terms of safety and success of treatment. Although this endoscopic series is small in number, it is likely that the percentage of patients in whom subsequent VP shunt placement is avoided by undergoing surgical removal of the cyst will be comparable to the suboccipatal craniotomy. Likewise, the treatment and avoidance of cyst-related ependymitis should be similar as well. The main advantage, then, to the endoscopic approach is that it is "less invasive" than the suboccipital craniotomy. No brain retraction is required, and the elimination of the occipital craniectomy and C-1 laminectomy reduces operating room time, blood loss, and postoperative surgery-related discomfort. As such, it is an ideal implementation of an endoscopic technique. 


\section{CONCLUSION}

For neurosurgical centers with the proper equipment and expertise, the endoscopic removal of cysts from the fourth ventricular should be the primary treatment of choice when surgery is not contraindicated.

\section{Acknowledgments}

The author is indebted to Antonio A. DeSalles, M.D., Ph.D., and John G. Frazee, M.D., for their editorial assistance.

\section{Disclosure}

The author has no financial interest in the instrumentation or equipment listed in the methodology.

\section{References}

1. Abad JM, Fernandez J, Bollar A, et al: Brain cysticercosis treated with praziquantel. Report of six cases. Acta Neurochir 93:88-91, 1988

2. Allcut DA, Coulthard A: Neurocysticercosis: regression of a fourth ventricular cyst with praziquantel. J Neurol Neurosurg Psychiatry 54:461-462, 1991

3. Apuzzo MLJ, Dobkin WR, Zee CS, et al: Surgical considerations in treatment of intraventricular cysticercosis. An analysis of 45 cases. J Neurosurg 60:400-407, 1984

4. Bandres JC, White AC Jr, Samo T, et al: Extraparenchymal neurocysticercosis: report of five cases and review of management. Clin Infect Dis 15:799-811, 1992

5. Bergsneider M: Transendoscopic instrumentation and techniques, in King WA, Frazee JG, De Salles AAF (eds): Endoscopy of the Central and Peripheral Nervous System. New York: Thieme, 1997, pp $16-22$

6. Bergsneider M, Frazee JG: Ventricular endoscopy, in De Salles AF, Lufkin RB (eds): Minimally Invasive Surgery of the Brain. New York: Thieme, 1997, pp 254-267

7. Carpio A, Santillán F, León P, et al: Is the course of neurocysticercosis modified by treatment with antihelminthic agents? Arch Intern Med 155:1982-1988, 1995

8. Colli BO, Martelli N, Assirati JA Jr, et al: Results of surgical treatment of neurocysticercosis in 69 cases. J Neurosurg 65:309-315, 1986

9. Colli BO, Pereira CU, Assirati JA, et al: Isolated fourth ventricle in neurocysticercosis: pathophysiology, diagnosis, and treatment. Surg Neurol 39:305-310, 1993

10. Couldwell WT, Apuzzo MLJ: Management of cysticercosis cerebri. Contemp Neurosurg 19:1-6, 1989

11. Couldwell WT, Zee CS, Apuzzo MLJ: Definition of the role of contemporary surgical management in cisternal and parenchymatous cysticercosis cerebri. Neurosurgery 28:231-237, 1991

12. Cuetter AC, Garcia-Bobadilla J, Guerra LG, et al: Neurocysticercosis: focus on intraventricular disease. Clin Infect Dis 24:157-164, 1997 
13. de Morais-Rêgo SF, Latuf NL: [Cysticercosis of the fourth ventricle simulating a posterior fossa neoplasm in cerebral scintillography. Report of a case.] Arq Neuropsiquiatria 36:371-374, 1978 (Por)

14. DeFeo D, Foltz EL, Hamilton AE: Double compartment hydrocephalus in a patient with cysticercosis meningitis. Surg Neurol 4:247-251, 1975

15. Del Brutto OH: Cysticercosis and cerebrovascular disease: a review. J Neurol Neurosurg Psychiatry 55:252-254, 1992

16. Del Brutto $\mathrm{OH}$, Sotelo J: Albendazole therapy for subarachnoid and ventricular cysticercosis. Case report. J Neurosurg 72:816-817, 1990

17. Del Brutto OH, Sotelo J, Roman GC: Therapy for neurocysticercosis: a reappraisal. Clin Infect Dis 17:730-735, 1993

18. Duplessis E, Dorwling-Carter D, Vidaillet M, et al: [Intraventricular neurocysticercosis. Apropos of 3 cases.] Neurochirurgie 34:275-279, 1988 (Fr)

19. Estañol B: Medical treatment of cerebral cysticercosis. Eur Neurol 37:125-126, 1997

20. Estañol B, Kleriga E, Loyo M, et al: Mechanisms of hydrocephalus in cerebral cysticercosis: implications for therapy. Neurosurgery 13:119-123, 1983

21. Fandiño J, Botana C, Fandiño C, et al: Clinical and radiographic response of fourth ventricle cysticercosis to praziquantel therapy. Acta Neurochir 111:135-137, 1991

22. Fandiño J, Rodríguez M, Pastor A, et al: [Cerebral cysticercosis. 10 cases.] Revue Neurologique 145:389-392, 1989 (Fr)

23. Gower DJ, Pollay M: Adverse postoperative events, in Apuzzo MLJ (ed): Brain Surgery. Complication Avoidance and Management. New York: Churchill Livingstone, 1993, pp 1691-1698

24. Kerin D, Zee CS, Tsai F, et al: Transventricular migration of cysticercal cyst during pneumoencephalography. Bull Clin Neurosci 48:61-84, 1983

25. Koziarski A, Kroh H, Olszewski E: [A case of cysticercosis of the IV cerebral ventricle.] Neurol Neurochir Polska 26:115-120, 1992 (Pol)

26. Lobato RD, Lamas E, Portillo JM, et al: Hydrocephalus in cerebral cysticercosis. Pathogenic and therapeutic considerations. J Neurosurg 55:786-793, 1981

27. Loyo M, Kleriga E, Estañol B: Fourth ventricular cysticercosis. Neurosurgery 7:456-458, 1980

28. Madrazo I, Flisser A: Cysticercosis, in Apuzzo MLJ (ed): Brain Surgery. Complication Avoidance and Management. New York: Churchill Livingstone, 1993, pp 1419-14130

29. Madrazo I, García-Rentería JA, Sandoval M, et al: Intraventricular cysticercosis. Neurosurgery 12:148-152, 1983

30. Madrazo I, Sanchez Cabrera JM, Maldanado Leon JA: Pipette suction for atraumatic extraction of intraventricular cysticercosis cysts. Technical note. J Neurosurg 50:531-532, 1979 
31. Martinez HR, Rangel-Guerra R, Arredondo-Estrada JH, et al: Medical and surgical treatment in neurocysticercosis a magnetic resonance study of 161 cases. J Neurol Sci 130:25-34, 1995

32. McCormick GF, Zee CS, Heiden J: Cysticercosis cerebri. Review of 127 cases. Arch Neurol 39:534-539, 1982

33. Neal JH: An endoscopic approach to cysticercosis cysts of the posterior third ventricle.

Neurosurgery 36:1040-1043, 1995

34. Neal JH: Endoscopic neurosurgery. West J Med 153:544, 1990

35. Obrador S: Cysticercosis cerebri. Acta Neurochir 10:320-364, 1962

36. Penagos P: Cirugia en Neurocisticercosis: Experiencia de 10 Anos en el Instituto Nacional de Neurologia Y Neurocirugia de Mexico. Dissertation. Mexico City: Universidad Nacional Autonoma de Mexico, 1988

37. Proaño JV, Madrazo I, García L, et al: Albendazole and praziquantel treatment in neurocysticercosis of the fourth ventricle. J Neurosurg 87:29-33, 1997

38. Robles C, Sedano AM, Vargas-Tentori N, et al: Long-term results of praziquantel therapy in neurocysticercosis. J Neurosurg 66:359-363, 1987

39. Sandoval M, Madrazo I, García-Rentería JA, et al: Obstruction of the ventricular catheter of a CSF shunt system due to the own cyst of Taenia solium. Arch Invest Med 21:95-958, 1990

40. Sotelo J, Marin C: Hydrocephalus secondary to cysticercotic arachnoiditis. A long-term follow-up review of 92 cases. J Neurosurg 66:686-689, 1987

41. Stern WE: Neurosurgical considerations of cysticercosis of the central nervous system. J Neurosurg 55:382-389, 1981

42. Torrealba G, Del Villar S, Tagle P, et al: Cysticercosis of the central nervous system: clinical and therapeutic considerations. J Neurol Neurosurg Psychiatry 47:784-790, 1984

43. Wei GZ, Li CJ, Meng JM, et al: Cysticercosis of the central nervous system. A clinical study of 1,400 cases. Chin Med J 101:493-500, 1988

44. Zee CS, Segall HD, Apuzzo MJL, et al: Intraventricular cysticercal cysts: further neuroradiologic observations and neurosurgical implications. AJNR 5:727-730, 1984

Manuscript received February 15, 1999.

Accepted in final form March 5, 1999.

Address reprint requests to: Marvin Bergsneider, M.D., Division of Neurosurgery, University of California Los Angeles, Box 957039, Los Angeles, CA 90095-7039. email:

bergsnei@ surgery.medsch.ucla.edu. 


\section{QuickTime Movies}

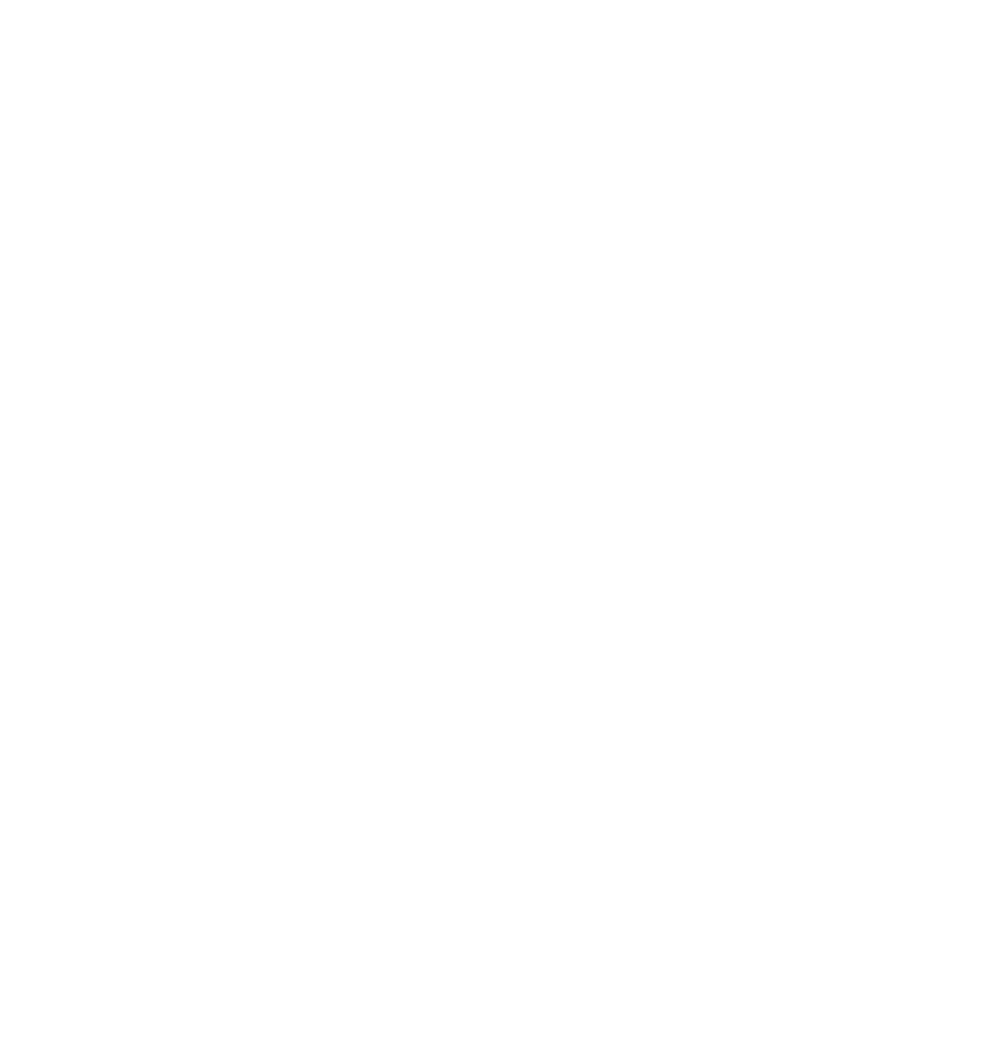

